\title{
MONITORAMENTO DA COMUNIDADE DE FORMIGAS APÓS PERTURBAÇÃO POR FOGO
}

\author{
Juliana Santos Carneiro ${ }^{1}$ e Evandro do Nascimento Silva \\ 1.Bolsista PIBIC/FAPESB, graduando em Ciências Biológicas, Universidade Estadual de Feira de Santana, e-mail: \\ carneiroj11.2@gmail.com \\ 1.Orientador, Departamento de Ciências Biológicas, Universidade Estadual de Feira de Santana, e-mail: \\ evandro.ecology@gmail.com
}

PALAVRAS-CHAVE: fogo; formigas; comunidades.

\section{INTRODUÇÃO}

O fogo pode causar respostas diversas nos ecossistemas. Ele tem grande importância para alguns ambientes, na dinâmica natural e na heterogeneidade espacial e temporal. O fogo é um dos distúrbios mais comuns que podem causar mudanças em grande escala na diversidade de espécies (Whelan 1995). Geralmente causa mudanças nas condições ambientais, na quantidade de biomassa, na diversidade de espécies e no funcionamento dos ecossistemas (Bengtsson et al 2000). O Parque Nacional da Chapada Diamantina (PNCD) é uma das áreas na Bahia mais atingidas por incêndios de origem natural e antrópica. O PNCD está localizado em uma região montanhosa na parte central da Bahia, onde muitas espécies endêmicas ocorrem dentro de ecossistemas de campos e savanas, especialmente em campos rochosos conhecidos como campos rupestres, onde os fogos antropogênicos são recorrentes (Gonçalves et al. 2011). Os campos rupestres são representados por um conjunto de comunidades predominantemente herbáceo-arbustivo que variam em função do relevo, microclima, profundidade de solo e natureza do substrato, o que dá um caráter de mosaico a estes tipos de vegetação (Vasconcelos 2009 \& Giuliett et al 1997).

Algumas pesquisas (como Jackson \& Fox, 1996) mostram que as formigas podem exibir respostas diversas a perturbação do fogo, isso será resultado das condições bióticas e abióticas. As formigas são insetos megadiversos. E são excelentes indicadores ambientais por serem organismos pequenos, sempre presentes e muito sensíveis às mínimas modificações do ambiente (Schowalter, 1995). As formigas apresentam grande potencial como bioindicadores, pois entre outras características, são insetos que apresentam grande diversidade correlacionada com a de outros componentes bióticos (Leal, 2005). As formigas que habitam em campos rupestres têm baixa mortalidade, pois elas, geralmente, vivem em ninhos subterrâneos onde ficam protegidas durante os incêndios. Em geral, o fogo é benéfico para as formigas, porque aumenta a disponibilidade de recursos, no momento em que a vegetação começa a rebrotar, elimina obstáculos à locomoção e assim há mais possibilidade de forrageamento (Andersen, 1988; Jackson \& Fox, 1996).

Esta pesquisa teve como objetivos estudar o efeito do fogo sobre a diversidade de formigas; caracterizar a riqueza de espécies de formigas antes e depois da perturbação por fogo; analisar a frequência de ocorrência das espécies mais abundantes de formigas. Com base nessas analises o que se espera é que com recuperação da vegetação a abundancia volte a diminuir em relação a primeira coleta após o fogo, mas que seria maior que a coleta antes do fogo. Em relação a riqueza se espera que esta seja maior que a observada na primeira coleta após o fogo (possivelmente reduzida a poucas espécies generalistas) e igual ou maior que a coleta antes do fogo, pois com o tempo a estrutura da vegetação poderá recuperar-se e ter uma comunidade de formigas com maior riqueza devido a adição de espécies especialistas. O trabalho justifica-se pela importância de suas informações para a gestão do parque, pois a grande incidência de incêndios no PNCD e em todo o ecossistema de campo rupestre, torna fundamental que se estabeleçam formas de manutenção do ecossistema e manejo da biodiversidade. Além de servir como uma linha de base de estudos sobre respostas das formigas em áreas de campo rupestres que passam por situações de incêndios. 


\section{MATERIAS E MÉTODOS}

Área de estudo - A pesquisa foi conduzida em duas áreas no sul do PNCD, entre os municípios de Mucugê e Ibicaraí. As áreas escolhidas são compostas por matriz de vegetação de campos rupestres, com solos arenosos e rasos, com inúmeros afloramentos rochosos. Em uma das áreas, chamada de Larga de Cima, foi instalado um experimento com fogo em novembro de 2015, num perímetro de $100 \mathrm{~m}^{2}$, manipulado pelo aluno de doutorado da UEFS, Thiago Araújo, junto com a coordenação do parque e os brigadistas para o controle das chamas. Nesta área foi realizada uma coleta antes do fogo, outubro de 2015, uma outra 90 dias depois, fevereiro 2016, e a última coleta realizada na área um ano após a primeira coleta. A segunda área escolhida, chamada Larga de Dentro, foi onde ocorreu o evento de fogo natural no mês de outubro de 2015. Foi feita uma campanha de coleta em fevereiro de 2016 onde houve fogo e em uma área vizinha sem fogo, e a última coleta foi feita apenas onde aconteceu o fogo, um ano após a primeira coleta. As parcelas para o experimento foram de $50 \times 50 \mathrm{~m}^{2}$, onde instalamos 60 armadilhas com 5 metros de distância entre elas, divididas em 6 transectos que se distanciavam em 10 metros.

Coleta de dados - Para caracterizar a comunidade de formigas foram utilizados dois métodos de coleta: Armadilhas do tipo Pitfall - foram instaladas 60 armadilhas que permaneceram por 48 horas em campo, como recomenda no Ants of the Leaf Litter Protocol ALL Protocol - proposto do Agosti et al. (2001). E armadilhas de isca com sardinha e mel também foram instaladas 60 armadilhas e permaneceram por apenas 1 hora, método utilizado por muitos pesquisadores como Frizzo et al. (2007).

Analise de dados - Os dados foram analisados através de teste não paramétrico, quiquadrado pelo software Past3, para calcular a semelhança entre métodos de coleta e o período, para as áreas escolhidas. As tabelas sobre presença e abundância de formigas nos pontos, foram feitas no Excel versão 2013.

\section{RESULTADOS E DISCUSSÃO}

A análise sobre a presença de formigas em cada área, obtivemos os seguintes resultados para Larga de Cima (LC) $\left(\chi^{2}=17,2 ;\right.$ G.L. $\left.=4 ; \rho=0,0017\right)$, esses resultados mostram que há diferenças significativas entre os períodos de coletas e armadilhas, portanto o fogo teve efeito sobre a ocorrência de formigas nos pontos de coleta. Para Larga de Dentro (LD) obtivemos os resultados seguintes $\left(\chi^{2}=3,75 ;\right.$ G.L. $\left.=4 ; \rho=0,44\right)$, esses dados mostram que não houve diferença significativa na segunda área entre os períodos de coleta, para cada tipo de armadilha. Mostrando que o fogo não teve efeito sobre essa parcela. Na LC a ocorrência de diminui na última campanha de coleta e na LD a ocorrência aumenta. Como pode ser observado no gráfico abaixo. 


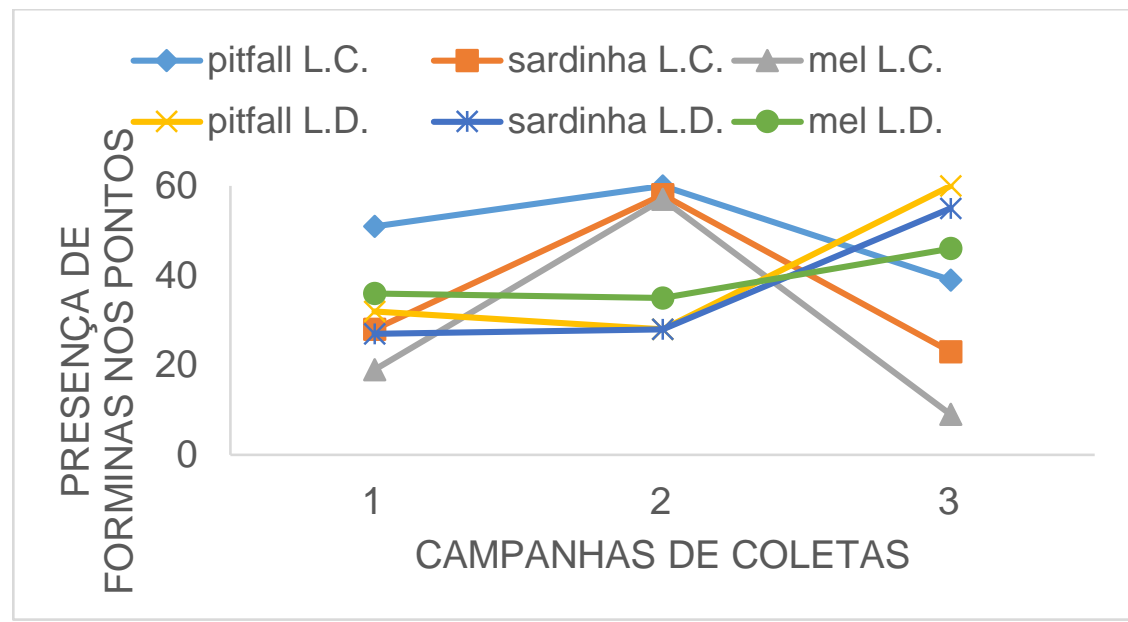

Figura 5: Ocorrência de formigas em três tipos de armadilha nas três áreas, durante as três campanhas de coleta.

Os resultados obtidos mostraram que há uma diferença em relação a presença de formigas nos pontos entre as duas áreas. Na LC na primeira campanha de coleta tivemos um número baixo de formigas presentes nos pontos, após o fogo houve um aumento para todos os métodos de coleta, já na terceira coleta (um ano após a primeira campanha) observamos que há uma grande queda na presença de formigas capturadas, o que já era esperado. Após o fogo há um aumento de recursos tróficos com o rebrotamento da vegetação, por essa razão podemos encontrar mais formigas no segundo momento. Outra explicação para esse aumento após o fogo que foi observado nessa pesquisa em campo e por Andersen (1988), depois do fogo algumas barreiras que ao forrageamento são eliminadas, o que possibilita às formigas maior alcance dos recursos alimentares. A terceira coleta teve o número menor, possivelmente devido à volta das barreiras com a recuperação da vegetação.

Para a segunda área, LD os resultados das primeiras coletas foram intermediários e muito semelhantes, mas na terceira coleta podemos observar (figura 5) há um grande aumento na presença de formigas para todos os métodos utilizados. Nas duas primeiras coletas (fevereiro de 2016) o solo estava encharcado no momento da coleta (dezembro de 2016) o solo estava encharcado. As formigas não forrageiam nessas condições ambientais. Elas, geralmente, procuram abrigos e recursos alimentares em arbustos ou árvores (Hölldobler \& Wilson 1990). Na última coleta o solo estava em boas condições para dispersão em busca de recursos. Outra explicação seria o aumento de recursos tróficos com o crescimento da vegetação e oferta de nectários extraflorais, bem como traz a presença de homópteros que são atendidos por formigas, as quais produzem honeydew, um recurso energético coletado pelas formigas.

Esses resultados são relevantes contribuições ao conhecimento dos efeitos do fogo sobre a diversidade faunística no PNCD. Os efeitos do fogo sobre comunidades bióticas devem ser estudados como forma de subsidiar ações de conservação biológica em ecossistemas sujeitos a tais perturbações. Os impactos desses eventos estocásticos sobre a biodiversidade da unidade de conservação ainda não são conhecidos. Este estudo, ainda que pontual, espacialmente falando, e focado em um único grupo taxonômico, as formigas, indica que nem todos os táxons são severamente afetados em sua ocorrência no ambiente, podendo restabelecer sua presença e também abundancia após evento de fogo.

\section{CONCLUSÃO}

Os resultados mostram que a comunidade de formigas pode apresentar diversas respostas, pois a presença delas depende das condições ambientais. Houve aumento de ocorrência na segunda coleta para área 1 LC, e na terceira houve uma queda que já era esperada, 
portanto, o fogo teve efeito sobre as formigas para essa área. Na área 2 LD, a ocorrência de formiga na primeira campanha de coleta (área atingida por fogo natural e área vizinha sem fogo) se manteve semelhante, com média de 30 pontos ocupados. Na última coleta na área queimada os pontos foram mais ocupados por formigas. Esses dados são uma análise apenas sobre ocorrência de formigas nos pontos amostrais. Podem haver mudanças nos resultados quando a analisarmos a riqueza e abundancia de espécies.

\section{REFERÊNCIAS}

AGOSTI, D. \& ALONSO, L.E., 2001. The all Protocol: a standard protocol for tha collection of ground-dwelling ants. Anet Newsletter, vol. 3, p. 8-11.

ANDERSEN, A.N. 1988. Immediate and longer-term effects of fire on seed predation by ants in sclerophyllous vegetation of southeastern Australia. Australian Journal of Ecology, 13, 285-293.

BENGSTSSON, J.; NILSON, S.G.; FRANC, A. \& MENOZZI, P. 2000. Biodiversity, disturbance, ecosystem function and management os European forests. Forest Ecology and Management, 132:39-50.

FRIZZO, T.L.M.; CAMPOS, R.I. \& VASCONCELOS, H.L. 2007. Efeito do fogo sobre a riqueza e abundância de formigas em área de cerrado no Brasil central. Biológico, São Paulo, v.69, suplemento 2, p.275-278.

GIULIETTI, A.M.; PIRANI, J.R. \& HARLEY,R.M. 1997. Espinhaço Range region, eastern Brazil. In: Davis, S.D.; Heywood, V.H; Herrera-MacBryde, O.; Villa-Lobos, J.; Hamilton, A.C. (Eds), Centres os plant diversity: a guide and strategy for their conservation. Volume 3. Information Press, Oxford, p. 397-404.

GONÇALVEZ, C.N.; MESQUITA, F.W.; LIMA, N.R.G.; COSLEPE, L.A. \& LINTOMEN, B.S. 2011. Recorrência dos incêndios e fitossociologia da vegetação em áreas com diferentes regimes de queima no Parque Nacional da Chapada Diamantina. Biodiversidade Brasileira 1: 161-179.

HÖLLDOBLER, B. \& WILSON, E. O. 1990. The Ants. Harvard University Press, Cambridge.

JACKSON, G.P. \& FOX, B.J. 1996. Comparison of regeneration following burning, clearing or mineral sand mining at Tomago, NSW: II. Succession of ant assemblages in a coastal forest. Australian Journal of Ecology, 21, 200-216.

LEAL, I. R. 2005. Formigas como indicadores de diversidade. In: Simpósio de Mirmecologia - Biodiversidade e Bioindicação, 27. Anais... Mato Grosso, CD-Rom.

SCHOWALTER, T. D. 1995. Canopy arthropod communities in relation to Forest age and alternative barvest pratctices in western oregon. Forest Ecology and Management, v. 78, p.15125.

VASCONCELOS, M.F. 2009. Avifauna dos campos rupestres e dos campos de altitudes do leste do Brasil: levantamento, padrões de distribuição geográfica, endemismo e conservação. Belo Horizonte: Universidade Federal de Minas Gerais.

WHELAN, R. 1995. The ecology of fire. Cambridge Studies in Ecology. Cambridge University Press, Cambridge.

YORK, A. 2000. Long-term effects of frequent low-intensity burning on ant communities in coastal black butt forests of southeastern Australia. Austral Ecology, 25, 83-98. 